Cite this: RSC Advances, 2013, 3, 17166

Received 22nd April 2013,

Accepted 16th July 2013

DOI: 10.1039/c3ra41964a

www.rsc.org/advances

\title{
Zirconia nanoparticles/ferroelectric liquid crystal composites for ionic impurity-free memory applications $†$
}

\author{
Achu Chandran, Jai Prakash, \$* Prasun Ganguly and Ashok M. Biradar
}

\begin{abstract}
We observed an ionic impurity-free memory effect using a zirconia nanoparticles (ZNPs)/ferroelectric liquid crystal (FLC) composite. The pure and ZNPs doped FLC cells have been analyzed by means of dielectric spectroscopy, polarizing optical microscopy and electrical resistance/conductivity measurements. The memory behavior in ZNPs/FLC composite was confirmed by dielectric dispersion, electrical, and optical studies, whereas dielectric loss spectra confirmed the disappearance of the low-frequency relaxation peak, which appears due to the presence of ionic impurities in FLC materials. The observed memory effect has been attributed to minimization of the depolarization field and ionic charges, whereas the reduction of ionic effects has been attributed to the strong adsorption of ionic impurities on the surface of ZNPs. The ZNPs dispersed in FLCs may play a role in trapping the impurity ions (minimize the depolarization fields) under applied voltage and cause a better memory effect in ZNPs doped FLC material. Moreover, the ion adsorption capability of ZNPs is found to be almost independent of temperature as the value of resistance did not change remarkably on increasing the temperature. The reduction of ionic impurities of FLCs by doping ZNPs did not show degradation over time, as we repeated the experiments on the same sample cells after many days and did not find ionic effects in the ZNPs doped FLC materials. These studies would be helpful to provide an idea for designing ionic impurity-free memory devices.
\end{abstract}

\section{Introduction}

Liquid crystals (LCs) have been a subject of immense research interest and practical importance because of their numerous applications, such as in flat panel displays, spatial light modulators, optical antennas, etc. ${ }^{1-3}$ Among all LC materials available to date, ferroelectric LCs (FLCs), which are well known for their good optical contrast, low threshold voltage, memory effect, fast response, etc., have attracted considerable attention from both fundamental and applied viewpoints. ${ }^{4-7}$ Metal oxides play a very important role in many areas of chemistry, physics and materials science because metal elements are able to form a diverse range of oxide compounds. $^{8-11}$ These can adopt a vast number of structural geometries with electronic structures that can exhibit metallic, semiconducting or insulating characters. Metal oxides are used in various technological applications, such as microelectronic circuits, sensors, piezoelectric devices, fuel cells, coat-

Polymeric and Soft Materials Section, CSIR-National Physical Laboratory, Dr K. S. Krishnan Road, New Delhi-110012, India. E-mail: jpsphysics@gmail.com $\dagger$ Electronic supplementary information (ESI) available. See DOI: 10.1039/ c3ra41964a

† Current address: Centre for Physical and Mathematical Sciences, Central University of Punjab, City Campus, Mansa Road, Bathinda-151 001, Punjab, India. ings for the passivation of surfaces against corrosion, and as catalysts. ${ }^{12-15}$ Metal oxide nanoparticles (NPs), interesting materials emerging from the field of nanotechnology, have attracted immense interest in the scientific community because they exhibit unique physical and chemical properties due to their limited size and a high density of corner or edge surface sites. ${ }^{10,16-18}$

Researchers around the world have prepared nanostructures for many oxides, but only a few of these have been systematically reported with respect to the nanostructure effect on the physical and/or chemical properties and behavior of the oxide materials. The most reported cases of metal oxide systems are $\mathrm{Al}_{2} \mathrm{O}_{3}, \mathrm{MgO}, \mathrm{ZrO}_{2}, \mathrm{CeO}_{2}$, and $\mathrm{TiO}_{2} \cdot{ }^{10,19}$ Some reported studies have also been devoted to other single oxide systems containing $\mathrm{Zn}, \mathrm{Fe}$, and $\mathrm{Sn}^{20-23}$ In recent years, thin films and NPs composed of zirconia material have been utilized in various devices such as electrodes, solar cells and transparent thin films because they offer many advantages including high dielectric permittivity, optical properties such as photoelectric conversion capability with the help of surface cations $^{24}$ and fluorescence emission properties under visible light, ${ }^{25}$ excellent thermal stability and chemical inertness. ${ }^{26-28}$ Materials scientists and technologists all around the world started to improve the dielectric and electro-optical properties of LCs by minute incorporation of metal oxide NPs. Kim and 
coworkers explored the doping effects of $\mathrm{ZrO}_{2}$ NPs (ZNPs) on the characteristics of LC devices. ${ }^{29}$ They demonstrated that the addition of ZNPs contributed to an improvement in electrooptic properties in nematic LC cells, such as lower voltage operation and faster response time. Park et al. introduced the use of zirconia in LC alignment for uniform and effective LC orientation. ${ }^{30}$ Another group reported the reduction of the threshold voltage of a twisted nematic LC cell which was caused by doping $\mathrm{MgO}$ and $\mathrm{SiO}_{2} \mathrm{NPs}$, and attributed the effect to the decrease in the order parameters. ${ }^{31}$ Sano et al. demonstrated the reduction in the operating voltage and response times of nematic LCs by doping the MgO NPs. ${ }^{32}$ To our knowledge, most of the reported work has been focused on nematic LCs. The doping of metal oxide NPs in FLCs has been rarely reported, except for our group's report in which the authors observed the effect of doping of alumina NPs in order to suppress the undesired ionic effect in FLCs. ${ }^{33}$

In this report, we have studied the doping effects of ZNPs in a FLC material, namely KCFLC 10S, and demonstrated the feasibility to fabricate ionic impurity-free memory devices based on ZNPs/FLC composite. The experimental results have been analyzed by means of dielectric spectroscopy, polarizing optical microscopy and electrical resistance/conductivity measurements. The observed memory effect in ZNPs/FLC composite was confirmed by dielectric dispersion, electrical, and optical studies whereas the reduction of ionic impurities in the FLC material has been confirmed by dielectric loss spectra and resistance/conductivity measurements. We attribute the observation of a memory effect to the minimization of depolarization field and ionic charges. The reduction of ionic effects has been attributed to the strong adsorption of ionic impurities on the surface of ZNPs. The applicability of FLC based ionic impurity-free memory devices using ZNPs has been systematically studied.

\section{Experimental}

\section{Liquid crystal sample cell fabrication}

The LC sample cells have been fabricated by using highly conducting (30 ohms/square) and optically transparent sputtered indium tin oxide (ITO) glass substrates. The desired (square) electrode patterns having an area of $0.45 \mathrm{~cm} \times 0.45$ $\mathrm{cm}$ were obtained by using a photolithographic (using positive photoresist) technique. The homogeneous alignment of LC sample cells has been achieved by using a conventional rubbed polyimide technique. The thickness of the cell was maintained by using $6 \mu \mathrm{m}$ thick Mylar spacers. Detailed experimental processes for the fabrication of LC sample cell are listed in the ESI. $\dagger$

\section{Details of $\mathrm{ZrO}_{2}$ nanoparticles and FLC mixture used}

Highly pure $\mathrm{ZrO}_{2}$ powder, which was synthesized by the sol-gel method and dispersed in water $\left(20\right.$ wt.\% $\mathrm{ZrO}_{2}$ and 80 wt.\% water), was purchased from M/s J. K. Impex, Mumbai, India. The average particle size of the as purchased $\mathrm{ZrO}_{2}$ was $50 \mathrm{~nm}$. The dispersed $\mathrm{ZrO}_{2}$ powders were then milled in a high-energy

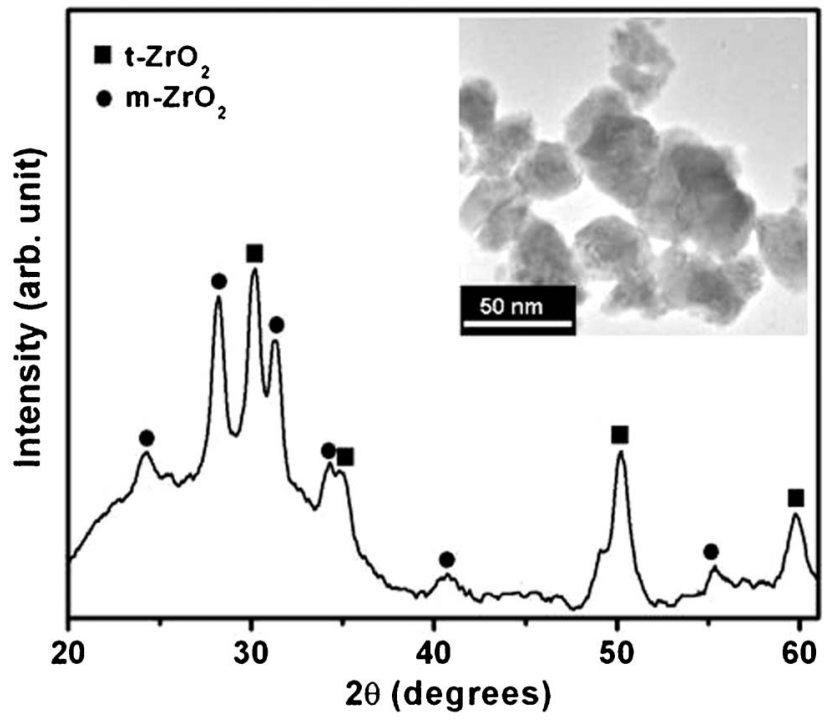

Fig. 1 XRD pattern of ball milled ZNPS. HRTEM micrograph of ball milled ZNPs is shown in the inset. Scale bar: $50 \mathrm{~nm}$.

planetary ball mill (PM 100, Retsch, Germany) for $10 \mathrm{~h}$ at a milling speed of $300 \mathrm{rpm}$ to further reduce the size of the $\mathrm{ZrO}_{2}$ nanopowders. Milling was done with high wear resistant 10 $\mathrm{mm} \mathrm{ZrO}_{2}$ balls in a zirconium oxide vial (M/s Retsch) with a ball-to-powder weight ratio of $10: 1$. The ball milled dispersion was diluted using DI water $(100 \mu \mathrm{l}$ of ball milled solution was added in $24.9 \mathrm{ml}$ of DI water) and ultrasonicated for about $1 \mathrm{~h}$ to maintain the homogeneity of the $\mathrm{ZrO}_{2}$ dispersion.

The X-ray diffraction (XRD) pattern of ball milled ZNPs, with a transmission electron microscopic (TEM) image of the same in the inset, is shown in Fig. 1. It is clear from the XRD of ZNPs that tetragonal and monoclinic phases coexist in the sample. The TEM image shown in the inset revealed the size and shape of the ZNPs after ball milling. The high magnification TEM image of ball milled ZNPs revealed rounded and oval shaped particles having a size of $\sim 30 \mathrm{~nm}$. The FLC mixture, KCFLC 10S, was purchased from Kingston Chemicals Limited, U.K. In KCFLC 10S, dialkyl ortho-difluoroterphenyl compounds were used as hosts and the addition of $10 \%$ of chiral dopant, cyanohydrin, to the host mixture generated a FLC mixture with a $\mathrm{SmC}^{*}$ phase. The chemical structures of these two major components are given below:
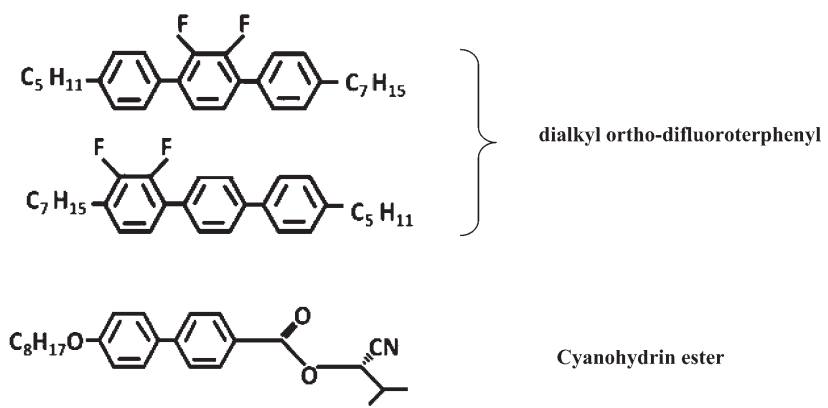

Cyanohydrin ester

The phase sequence of the FLC mixture is as follows: ${ }^{33}$ 
Table 1 Material parameters of FLC mixture, KCFLC 10S

\begin{tabular}{ll}
\hline Parameter/property & Values \\
\hline Spontaneous polarization & $31 \mathrm{nC} \mathrm{cm} \mathrm{cm}^{-2}$ \\
Rotational viscosity & $\sim 285 \mathrm{mPa} \cdot \mathrm{s}$ \\
Optical tilt angle & $23^{\circ}$ \\
Helical pitch & $>2 \mu \mathrm{m}$ \\
Optical anisotropy (birefringence) & 0.18 \\
\hline
\end{tabular}

$$
\text { cryst } \stackrel{<5^{\circ} \mathrm{C}}{\longrightarrow} \mathrm{SmC}^{*} \stackrel{64.5^{\circ} \mathrm{C}}{\longrightarrow} \mathrm{SmA}^{*} \stackrel{99.5^{\circ} \mathrm{C}}{\longrightarrow} \mathrm{N} \stackrel{112^{\circ} \mathrm{C}}{\longrightarrow} \text { iso }
$$

where cryst is the crystalline phase, $\mathrm{SmC}^{*}$ is the chiral smectic C phase, $\mathrm{SmA}^{*}$ is the chiral smectic A phase, $\mathrm{N}$ is the nematic phase, and iso is the isotropic phase. The other parameters of the FLC mixture are given in Table 1. The ZNPs/FLC composite having 4 wt $\%$ of $\mathrm{ZrO}_{2}$ nanopowders was prepared by adding $200 \mu \mathrm{l}$ of dispersed ball milled $\mathrm{ZrO}_{2}$ NPs (160 $\mu \mathrm{g}$ of $\mathrm{ZrO}_{2} \mathrm{NPs}$ ) in $4 \mathrm{mg}$ of FLC material, KCFLC 10S, through a drop by drop method. The mixture was then ultrasonicated for about $40 \mathrm{~min}$ in the isotropic phase of the FLC material to ensure the homogeneous dispersion of $\mathrm{ZrO}_{2} \mathrm{NPs}$ in the FLC host material. The pure and ZNPs doped FLC materials were injected into the LC sample cell via capillary force above the isotropic temperature of FLC material. To assess the thermal stability of the ZNPs/FLC composite, we performed thermogravimetric analysis (TGA) studies. Detailed TGA results are given in the ESI. $\dagger$

\section{Apparatus and measurements}

The dielectric permittivity $\left(\varepsilon^{\prime}\right)$ and dielectric loss factor $(\tan \delta)$ of pure and doped cells have been measured using an impedance analyzer $6540 \mathrm{~A}$ (Wayne Kerr, U. K) in a frequency range of $20 \mathrm{~Hz}-1 \mathrm{MHz}$. JULABO F-25 HE equipment was used for controlling the temperature with a temperature stability of $\pm 0.01{ }^{\circ} \mathrm{C}$. The sample holder containing the sample cells was kept thermally isolated from the external sources. The optical micrographs of the sample cells were taken with the help of a polarizing optical microscope (Ax-40, Carl Zeiss, Germany) fitted with a charge coupled device camera (CCD). For electrical response, electrical pulses of triangular shape and generated from a function generator were applied to the sample. For optical response, the sample was mounted on a polarizing microscope and the transmission of normally incident polarized light through the sample and analyzer was monitored with a photodiode. The time delayed square pulse generated from the function generator was applied to the sample and studied using a storage oscilloscope (HAMEG, HM 1507-3) interfaced with the computer via SP-107 software. High resolution transmission electron microscopy (HRTEM) experiments were performed using an HRTEM model Tecnai G2 F30 STWIN operated at the electron accelerating voltage of $300 \mathrm{kV}$ using a field emission gun as the electron source. XRD was performed at room temperature in the scattering angular

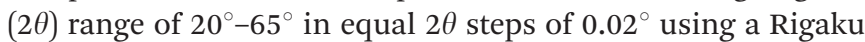
Diffractometer with $\mathrm{Cu}-\mathrm{K} \alpha(\lambda=1.54 \AA)$. TGA studies were performed using TGA/SDTA 851 (Mettler Toledo) in a nitrogen gas environment with temperature increase at a rate of $10{ }^{\circ} \mathrm{C}$ $\min ^{-1}$ from $25{ }^{\circ} \mathrm{C}$ to $300{ }^{\circ} \mathrm{C}$.

\section{Results and discussion}

\section{Memory effect in ZNPs doped FLC material}

Dielectric spectroscopy is a better tool than electro-optical studies as the memory effect in FLCs was visible and easily detectable by means of dielectric permittivity when bias was removed from the sample cell. It has been found that the presence of NPs can alter the dielectric behavior dramatically. ${ }^{34-36}$ Fig. 2 shows the $\varepsilon^{\prime}$ as a function of frequency in pure and ZNPs doped FLC material. As shown in Fig. 2(a), upon the change in bias voltage of the measuring field from 0 to $15 \mathrm{~V}$, the dielectric permittivity decreases to a minimum due to the suppression of the phason (Goldstone) mode, which occurs due to phase fluctuation of the molecules. ${ }^{25}$ Again on applying $0 \mathrm{~V}$ bias the $\varepsilon^{\prime}$ appears the same as it was before applying the bias. This confirms that the cell does not remain in a stable (or memory) state, and hence no memory effect is observed in the pure FLC material. In the case of ZNPs doped FLCs, the cell remains in the memory state to some extent, which is clearly shown in Fig. 2(b). The polarizing optical micrographs also
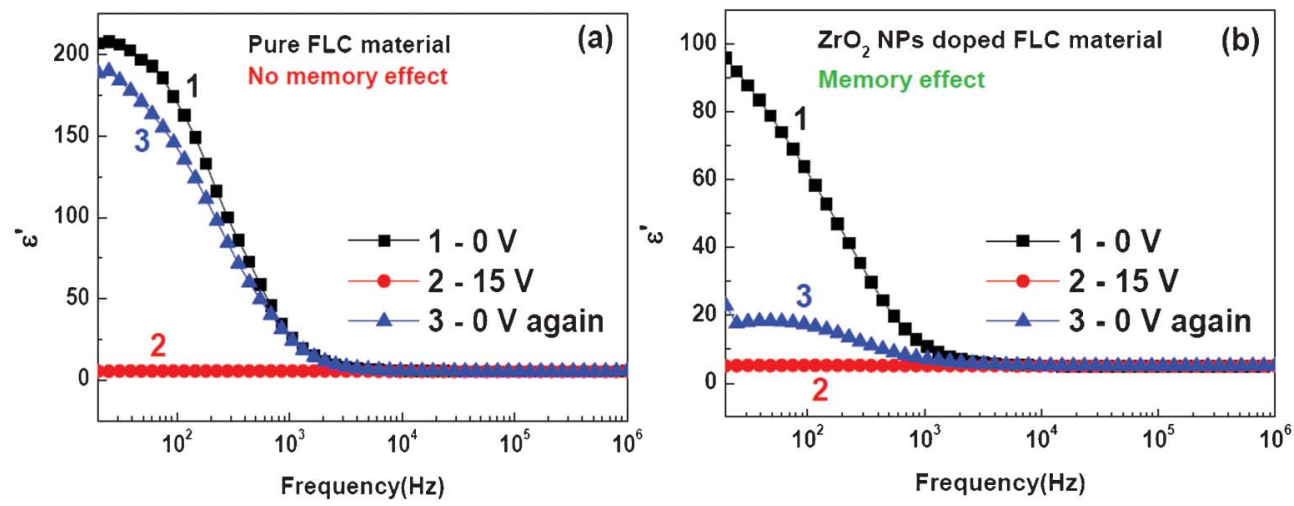

Fig. 2 Dielectric dispersion spectra (Dielectric permittivity, $\varepsilon^{\prime}$, as a function of frequency) at room temperature $\left(27^{\circ} \mathrm{C}\right.$ ) of (a) pure FLC material sample cell of thickness $6 \mu \mathrm{m}$ and (b) ZNPs doped FLC cell of the same thickness. (curve 1: at $0 \mathrm{~V}$, curve 2: at $15 \mathrm{~V}$ and curve 3: at $0 \mathrm{~V}$ again). 

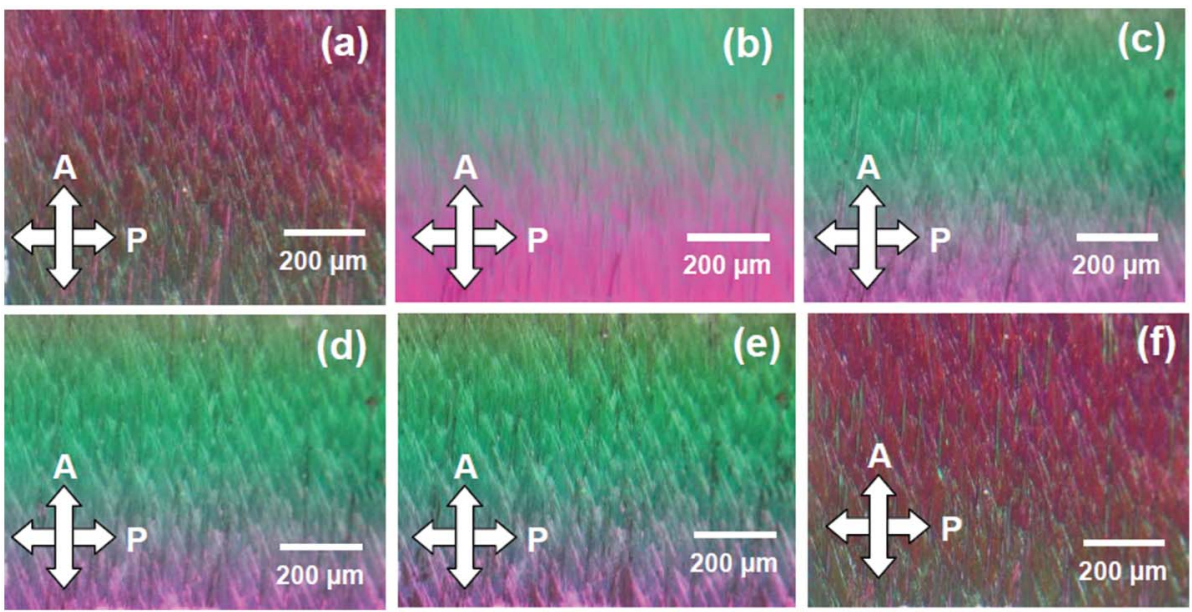

Fig. 3 Polarizing optical micrographs of $6 \mu \mathrm{m}$ ZNPs doped FLC memory cell at room temperature ( $27^{\circ} \mathrm{C}$ ) at (a) $0 \mathrm{~V}$, (b) $15 \mathrm{~V}$ bias, (c) $10 \mathrm{~s}$ after removal of bias, (d) 1 min after removal of bias (e) $10 \mathrm{~min}$ after removal of bias and (f) $0 \mathrm{~V}$ again. scale bar: $200 \mu \mathrm{m}$. Crossed arrows represent crossed polarizer (P) and analyzer (A).

reveal similar information confirming the memory effect in ZNPs doped FLC material. The electro-optical textures of ZNPs doped FLC material were observed in the deep SmC* phase by the application of $15 \mathrm{~V}$ bias under the polarizing optical microscope. Fig. 3 shows that ZNPs doped FLC clearly exhibit a memory effect.

Fig. 3(a) shows the scattering state (dark state) before any bias application to the cell. A complete switch to the bright state was achieved upon the application of $15 \mathrm{~V}$ bias [Fig. 3(b)]. The state $10 \mathrm{~s}$ after the removal of bias is shown in Fig. 3(c). Fig. 3(d) (which was taken $1 \mathrm{~min}$ after the removal of bias) shows that the memory was retained even after the removal of bias. Even after a time gap of 10 min the last memory state remains the same [Fig. 3(e)]. Once the cell switches to bright/ dark states, it tends to remain in that state for a period of time. The memory state in the ZNPs doped FLC samples was switched back to the original state (scattered state) after 15 min [Fig. 3(f)].

The memory effect in ZNPs doped FLC material was further confirmed by an optical response. Fig. 4 shows the optical response of pure and ZNPs doped FLC sample cells respectively which was inferred by applying time delayed positive and negative square pulses at different frequencies and at a fixed voltage. As one can see from Fig. 4(a and b), there is no memory effect in the pure FLC material at frequencies of 10 and $100 \mathrm{~Hz}$. The output response remains the same as the applied input time delayed square pulse. In the case of ZNPs doped FLC samples, a complete memory effect was observed in the entire frequency range as shown in Fig. 4(c and d). As seen in Fig. 4(c and d), the optical transmission changes from maximum to minimum as the applied field reverses its polarity and there is almost no change when the applied field attains its $0 \mathrm{~V}$ state. However there is slight degradation in the memory at higher frequencies because the memory effect in FLC is not favorable at higher frequencies. ${ }^{38}$

The observation of a memory effect in ZNPs doped FLC material has been attributed to the minimization of the depolarization field in doped samples. In order to confirm the minimization of the depolarization field, we have studied the electrical response of pure and ZNPs doped FLC sample cells at different frequencies and a fixed voltage on the application of triangular pulses to the sample cells. Fig. 5 shows the electrical response of pure and ZNPs doped FLC samples respectively at a fixed voltage (of $20 \mathrm{~V}$ ) and frequencies of 10 and $100 \mathrm{~Hz}$. As can be seen from Fig. 5(a and b), there is no symmetric polarization peak observed in the case of pure FLC material. There is nonlinearity in the output response of the pure FLC sample. Such a type of nonlinearity is due to the generation of a depolarization field to reverse the direction of spontaneous polarization..$^{37,39}$ The depolarization field is caused by the charges generated on the surface of bounding glass plates as a result of attaining stable states when an electric field is applied to the sample. This generates free
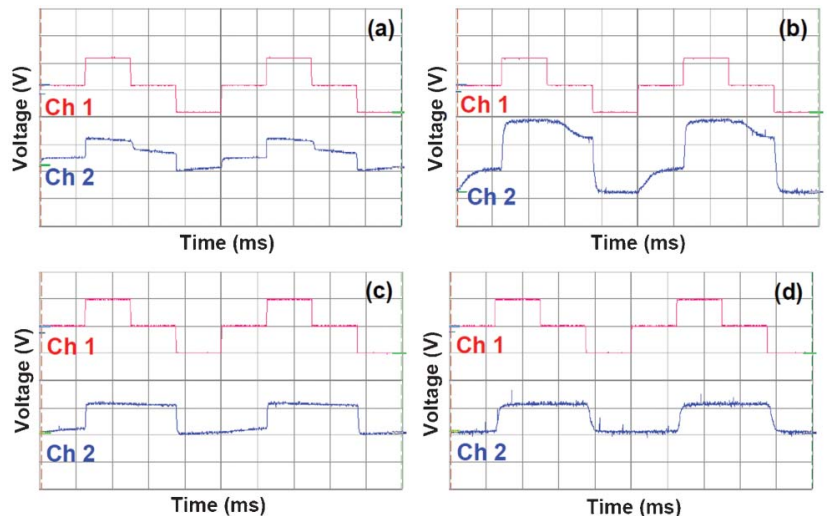

Fig. 4 Optical response of the pure FLC material at room temperature in a $6 \mu \mathrm{m}$ cell at $20 \mathrm{~V}_{\mathrm{pp}}$ at (a) $10 \mathrm{~Hz}$ (Ch 1: $5 \mathrm{~V} /$ div, Ch 2: $5 \mathrm{~V} /$ div, time: $20 \mathrm{~ms}$ ) and (b) 100 $\mathrm{Hz}$ (Ch 1: $10 \mathrm{~V} /$ div, Ch 2: $0.02 \mathrm{~V} /$ div, time: $5 \mathrm{~ms}$ ). Response of ZNPs doped FLC material at room temperature in a cell of the same thickness at $20 \mathrm{~V}_{\mathrm{pp}}$ at (c) 10 $\mathrm{Hz}$ (Ch 1: $10 \mathrm{~V} /$ div, Ch 2: $0.05 \mathrm{~V} /$ div, time: $20 \mathrm{~ms}$ ) and (d) $100 \mathrm{~Hz}$ (Ch 1: $10 \mathrm{~V} / \mathrm{div}$, Ch 2: $0.05 \mathrm{~V} /$ div, time: $5 \mathrm{~ms}$ ). Ch1 shows driving square voltage and Ch2 shows its optical response. The time scale per division is shown on the $x$-axis, which is same for both channels. 

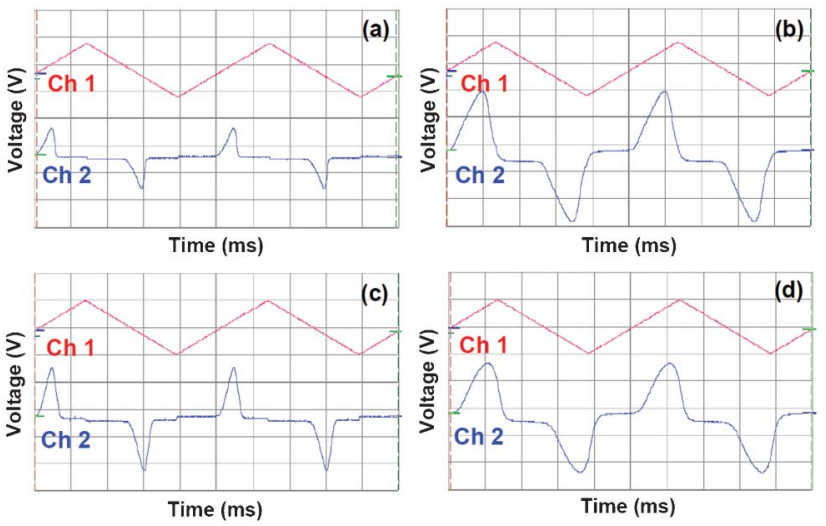

(c)

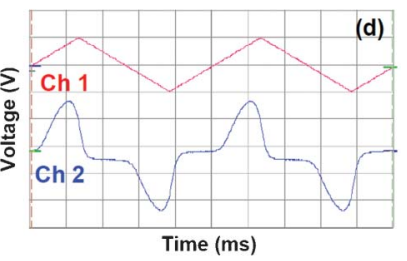

Fig. 5 Electrical response of pure $\mathrm{FLC}$ material at room temperature in a $6 \mu \mathrm{m}$ cell at $20 \mathrm{~V}_{\mathrm{pp}}$ at (a) $10 \mathrm{~Hz}$ (Ch 1: $5 \mathrm{~V} / \mathrm{div}, \mathrm{Ch} 2: 5 \mathrm{~V} / \mathrm{div}$, time: $20 \mathrm{~ms}$ ) and (b) 100 $\mathrm{Hz}$ (Ch 1: $10 \mathrm{~V} / \mathrm{div}$, Ch 2: $2 \mathrm{~V} /$ div, time: $5 \mathrm{~ms}$ ). Response of ZNPs doped FLC material at room temperature in a cell of the same thickness at $20 \mathrm{~V}_{\mathrm{pp}}$ at (c) 10 $\mathrm{Hz}$ (Ch 1: $5 \mathrm{~V} / \mathrm{div}, \mathrm{Ch} 2: 5 \mathrm{~V} /$ div, time: $20 \mathrm{~ms}$ ) and (d) $100 \mathrm{~Hz}$ (Ch 1: $10 \mathrm{~V} / \mathrm{div}$, Ch 2: $2 \mathrm{~V} /$ div, time: $2 \mathrm{~ms}$ ). Ch 1 shows driving triangular voltage and $\mathrm{Ch} 2$ shows its electrical response. The time scale per division is shown on the $x$-axis, which is same for both channels.

charges on the bounding glass plates, which in turn generates a depolarization field. The influence of depolarization field is clearly seen [Fig. 5(a and b)] by the nonlinear polarization reversal current response of the FLC cell to a linearly varying triangular pulse. Moreover, it has been observed earlier that if the pulse width of the external voltage is larger than approximately a few hundred $\mu$ s, then accumulation of excess ions at the interface between the FLC medium and the alignment layer takes place. ${ }^{40}$ These excess ions generate an external field which increases the depolarization field. The field generated by these ions is also responsible for the nonlinearity in the output response of pure FLC samples. Due to the presence of the depolarization field, the memory effect could not be observed in the pure FLC material. In case of ZNPs doped FLC sample cell, a symmetric polarization peak was observed which is clearly reflected in Fig. 5 (c and d). There is perfect linearity hence the depolarization effect is minimized in such types of sample. The minimization of the depolarization field causes a memory effect in ZNPs doped FLC material. The ZNPs dispersed in FLCs may play a role in trapping the impurity ions (minimizing the depolarization fields) under applied voltage; thus the NPs induced a better memory effect in ZNPs doped FLC material. ${ }^{27}$ The details of trapping the impurity ions by ZNPs have been explained in a subsequent section. Furthermore, the ZNPs doped in FLCs interacted strongly with both the NPs and FLC molecules. This interaction is affected by enhanced anchoring and the structure ordering of FLC molecules. As the sizes of the ZNPs $(\sim 30 \mathrm{~nm})$ used are larger than that of FLC molecules, the interaction of ZNPs and FLC molecules has a higher dipole moment. The higher dipole moment causes a higher electrical torque of interacted ZNPs and FLC molecules. Therefore, the ZNPs/FLC composite has an enhanced electro-optic memory effect.

\section{Reduction of ionic impurities of FLC through the doping of ZNPs}

The occurrence of undesired impurity ions in LC materials is a major problem which needs to be overcome, as these impurity ions can cause the degradation of LC material based electrooptic devices. ${ }^{41-43}$ These impurity ions in LC materials arise from the LC mixture and enter within LCs either through the atmosphere or alignment layer or during their synthesis. The impurity ions within LCs generate an electric field which could lead to polar surface interactions and change the anchoring energy and driving voltage. ${ }^{44,45}$ These ions create problems such as gray-level shift, image sticking and slow response times of the LC device. ${ }^{46}$ Therefore, it becomes quite important to reduce the undesired ionic impurities in order to obtain efficient and better electro-optic devices based on LCs/FLCs. The LC researchers have made remarkable efforts in the direction of minimization of ionic impurities by doping various nanomaterials, such as insulating nanoparticles, $\mathrm{ZnO}$, $\mathrm{TiO}_{2}$, and $\mathrm{Si}_{3} \mathrm{~N}_{4}$ nanoparticles, inorganic montmorillonite nano-platelets, and CNTs into the LC material. ${ }^{47-51}$ More recently, our group has tried to reduce the undesired impurity ions in FLC materials by doping of alumina NPs and copper oxide decorated MWCNTs, and observed the reduction of the former to some extent. ${ }^{33,52}$
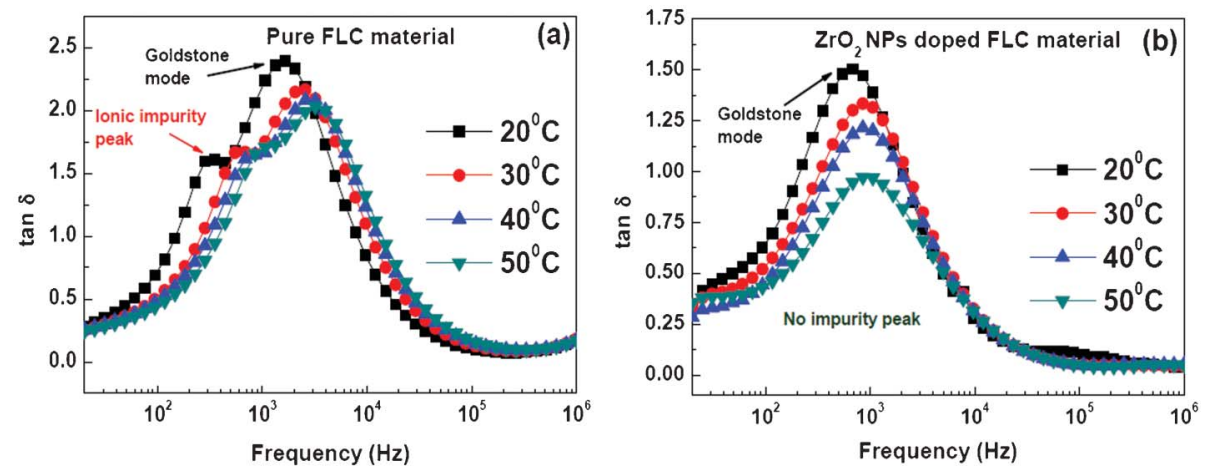

Fig. 6 Dielectric absorption spectra (dielectric loss factor, $\tan \delta$, with frequency) at different temperatures for homogeneously aligned $6 \mu \mathrm{m}$ thick cells of (a) pure and (b) ZNPs doped FLC material. 

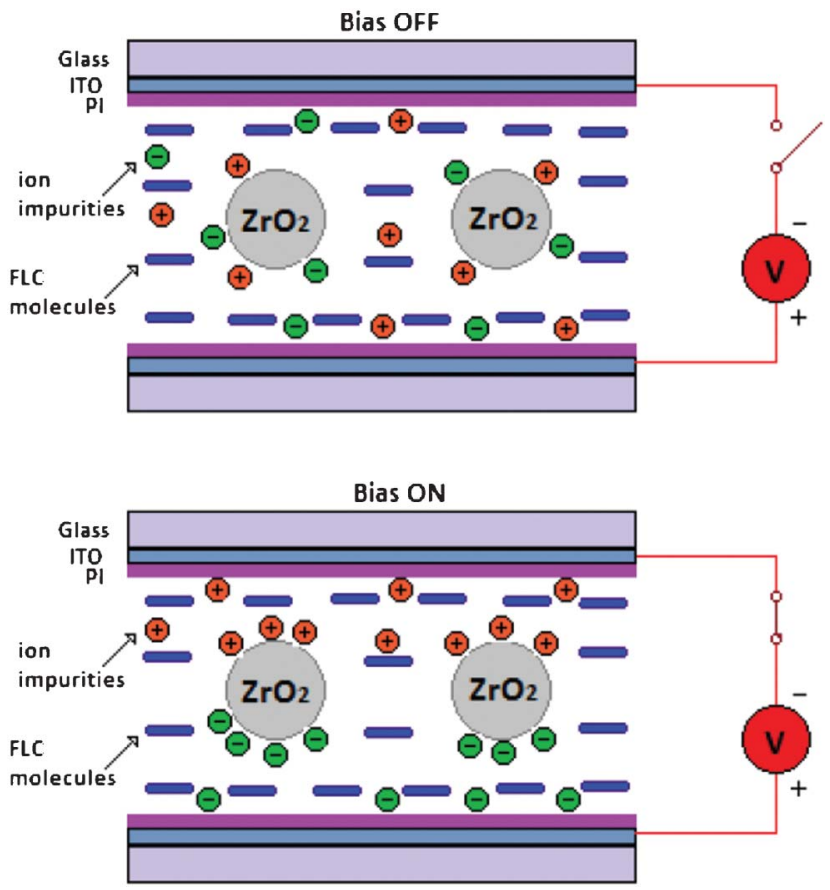

Fig. 7 Schematic depiction of trapping mechanism of internal impurity ions in a $\mathrm{FLC}$ cell with doping of $\mathrm{ZrO}_{2}$ nanoparticles.

The FLC material used in this study possesses ionic impurities which may cause the degradation of the display devices based on it. ${ }^{33}$ Fig. 6 shows the behavior of $\tan \delta$ with frequency at different temperatures for $6 \mu \mathrm{m}$ thick homogeneously aligned cells of pure and ZNPs doped FLC material. As shown in Fig. 6(a), two relaxation peaks were observed in the case of pure FLC material, of which the peak at the high frequency side corresponds to the Goldstone mode, whereas the low frequency peak is related to the low frequency relaxation of the FLC material. This low frequency mode cannot be assigned either as a Goldstone mode or the mode purely due to space charge accumulation near the substrate surface. $^{53}$ The appearance of the low-frequency mode in another FLC material, namely KCFLC 7S, was due to the ionization-recombination assisted diffusion of slow ions in a planar alignment configuration. ${ }^{53}$ The presence of a low frequency peak in the case of KCFLC $10 \mathrm{~S}$ may be due to ionization-recombination assisted diffusion of slow ions or molecular diffusion of fast ions. Detailed studies showing the behavior of the low frequency peak with temperature and the DC bias field are under investigation and will be published elsewhere. The ZNPs effectively suppressed the impurity ions present in the FLC material. As can be clearly seen from Fig. 6(b), the low-frequency mode has disappeared by doping ZNPs into the FLC material.

The schematic illustration of trapping of ions of the FLC material by ZNPs has been depicted in Fig. 7. The disappearance of the low frequency mode in the case of ZNPs doped FLC material suggested the adsorption of ions responsible for the generation of low-frequency relaxation.

In order to confirm the suppression of impurity ions in the FLC material, we observed the behavior of electrical resistance of the pure and ZNPs doped FLC material. Fig. 8 shows the behavior of resistance of pure and ZNPs doped FLC material with frequency at different temperatures. In the case of the pure FLC material, the resistance was observed as around 9 $\mathrm{M} \Omega$ at $20 \mathrm{~Hz}$ frequencies, which was decreased upon increasing the temperature [Fig. 8(a)]. The variation of resistance with frequency at different temperatures for ZNPs doped FLC material is shown in Fig. 8(b). The resistance of ZNPs doped FLC material was observed to be around $17 \mathrm{M} \Omega$ at $20 \mathrm{~Hz}$ frequency at room temperature, which is higher than that of the pure FLC material. The increased value of resistance in the case of ZNPs doped FLC material disguised the reduction of impurity ions due to doping of the ZNPs. Moreover, the value of resistance did not change remarkably on increasing the temperature from $25{ }^{\circ} \mathrm{C}$ to $45{ }^{\circ} \mathrm{C}$ in the case of ZNPs doped FLC material, suggesting that the ion adsorption capability of ZNPs is almost independent in these temperature ranges.

We further confirmed the suppression of impurity ions of FLC material by observing the electrical conductivity of pure and ZNPs doped FLC materials. Electrical resistance is characteristic of the particular cell, whereas electrical conductivity is characteristic of the material. We calculated and plotted the electrical conductivity of pure and ZNPs doped FLC material. Fig. 9 shows the electrical conductivity behavior of
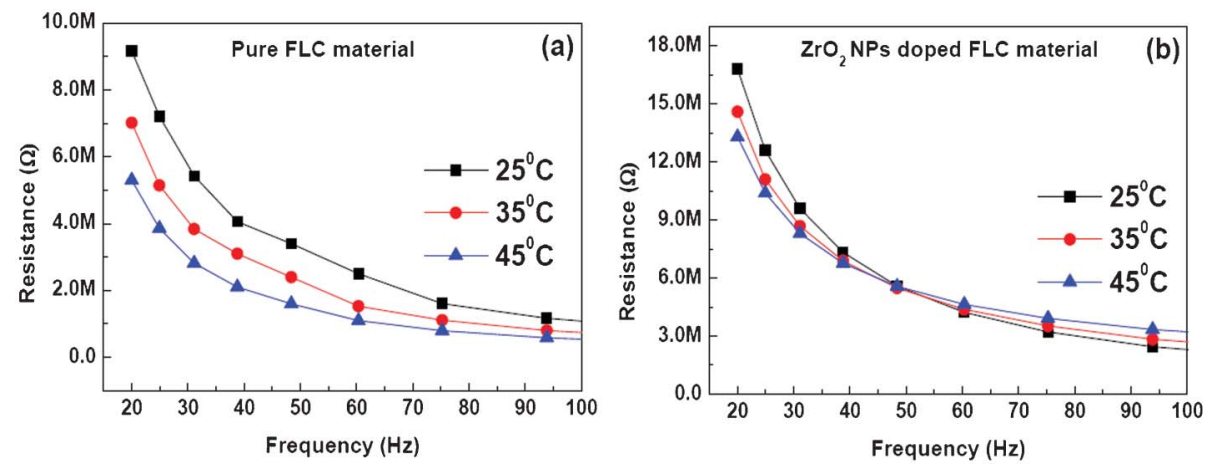

Fig. 8 Behavior of electrical resistance (R) of (a) pure and (b) ZNPs doped FLC material with frequency for homogeneously aligned $6 \mu$ m thick cells at different temperatures. 

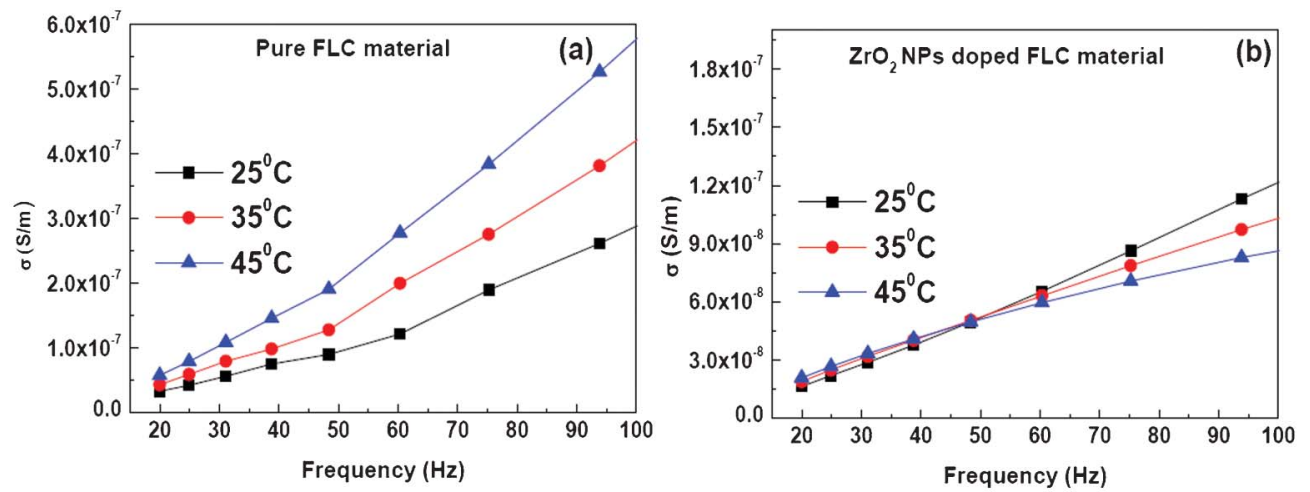

Fig. 9 Electrical conductivity $(\sigma)$ behavior of (a) pure and (b) ZNPs doped FLC material with frequency for homogeneously aligned $6 \mu$ m thick cells at different temperatures.

pure and ZNPs doped FLC material with frequency at different temperatures. It is clear from the figure that the conductivity value was increased with increasing temperature for both pure and doped samples. In the case of ZNPs doped FLC material [Fig. 9(b)], the conductivity value was significantly reduced. For instance, at $45{ }^{\circ} \mathrm{C}$ and $60 \mathrm{~Hz}$ frequency, its value was $278 \times$ $10^{-9} \mathrm{~S} \mathrm{~m}^{-1}$ (siemens per metre) for pure FLC [Fig. 9(a)] while for ZNPs doped FLC material it reduced to $60 \times 10^{-9} \mathrm{~S} \mathrm{~m}^{-1}$ [Fig. 9(b)].

The suppression of impurity ions in the FLC material studied by doping ZNPs into the former have been confirmed by dielectric loss spectra, electrical resistance and conductivity measurements. The reduction of ionic impurities of FLCs by doping ZNPs did not show degradation over time. The experiments were repeated on the same sample cells after many days, and ionic effects were not found in the ZNPs doped FLC materials with no degradation in contrast. The suppression of impurity ions of the host FLC medium has been attributed to the adsorption/trapping of ions by the guest ZNPs. This study describes the removal of ionic impurities in ZNPs/FLC system by means of adsorption/trapping phenomena, which requires further careful investigations to understand the exact mechanism of adsorption/trapping.

\section{Conclusions}

We observed an ionic impurity-free memory effect based on ZNPs doped FLC material and proposed the feasibility to fabricate impurity ion-free electro-optic memory devices. The pure and ZNPs doped FLC cells have been analyzed by means of dielectric spectroscopy, polarizing optical microscopy and electrical resistance/conductivity measurements. The observed memory effect has been attributed to minimization of depolarization field and ionic charges. The reduction of ionic effects has been attributed to the strong adsorption/trapping of ionic impurities through the ZNPs in the FLC material. The applicability of FLC based ionic impurity-free memory devices using ZNPs was systematically studied. These studies will be helpful to provide an idea for designing impurity ion-free electro-optic memory devices based on the ZNPs/FLC system.

\section{Acknowledgements}

The authors sincerely thank Professor R. C. Budhani, Director, CSIR-National Physical Laboratory, New Delhi for continuous encouragement and interest in this work. We also thank Dr Amit Chaudhary, Dr Ajay Kumar, Dr Puja Goel, Ms. Anu Malik, Mr. Tilak Joshi, and Mr. Shashank Tripathi for fruitful discussions. Authors A.C. and P.G. are thankful to the Council of Scientific and Industrial Research (CSIR), India for providing financial assistance through research fellowship schemes: CSIR-PGRPE/2011-13 and HRDG/CSIR-Nehru PDF/ PS/EMR-I/01/2011 respectively, and author J.P. is grateful to the Department of Science and Technology for supporting this work under INSPIRE Faculty Award (DST/INSPIRE Faculty Award/2011) through INSPIRE Faculty Scheme of DST [IFA-PH$10]$.

\section{References}

1 R. B. Meyer, L. Liebert, L. Strzelecki and P. Keller, J. Phys., Lett., 1975, 36, L69.

2 N. A. Clark and S. T. Lagerwall, Appl. Phys. Lett., 1980, 36, 899.

3 S. Garoff and R. B. Meyer, Phys. Rev. Lett., 1977, 38, 848.

4 V. Lapanik, V. Bezborodov, S. Timofeev and W. Haase, Appl. Phys. Lett., 2010, 97, 251913.

5 J. Prakash, A. Choudhary, S. Kaur, D. S. Mehta and A. M. Biradar, Phys. Rev. E: Stat., Nonlinear, Soft Matter Phys., 2008, 78, 021707.

6 S. T. Langerwall, Ferroelectric and Antiferroelectric Liquid Crystals, Wiley-VCH, Verlag Gmbh, Germany, 1999.

7 T. Joshi, A. Kumar, J. Prakash and A. M. Biradar, Appl. Phys. Lett., 2010, 96, 253109.

8 H. H. Kung, Transition Metal Oxides: Surface Chemistry and Catalysis, Elsevier, Amsterdam, 1989.

9 V. E. Henrich and P. A. Cox, The Surface Chemistry of Metal Oxides, Cambridge University Press, Cambridge, UK, 1994.

10 J. A. Rodríguez and M. Fernández-García (ed.), Synthesis, Properties and Applications of Oxide Nanoparticles, Wiley, New Jersey, 2007. 
11 C. M. Lukehart and R. A. Scott (ed.), Nanomaterials: Inorganic and Bioinorganic Perspectives, John Wiley and Sons, Chichester, UK, 2008.

12 J. Robertson, Rep. Prog. Phys., 2006, 69, 327.

13 Z. L. Wang and J. Song, Science, 2006, 312, 242-246.

14 A. M. Föller, Magnesium Oxide and its Applications, Vollhardt, Berlin, 1978.

15 M. E. Franke, T. J. Koplin and U. Simon, Small, 2006, 2, 36.

16 M. Valden, X. Lai and D. W. Goodman, Science, 1998, 281, 1647.

17 J. A. Rodriguez, G. Liu, T. Jirsak Hrbek, Z. Chang, J. Dvorak and A. Maiti, J. Am. Chem. Soc., 2002, 124, 5247.

18 M. L. Trudeau and J. Y. Ying, Nanostruct. Mater., 1996, 7, 245.

19 J. Gangwar, K. K. Dey, Komal Praveen, S. K. Tripathi and A. K. Srivastava, Adv. Mater. Lett., 2011, 2(6), 402.

20 R. Viswanaha, S. Sapra, B. Satyani, B. N. Der and D. D. Sarma, J. Mat. Sci., 2004, 14, 661.

21 X. Wu, P. Jiang, Y. Ding, W. Cai, S. S. Xie and Z. L. Wang, Adv. Mater., 2007, 19, 2319.

22 N. Feltin and M. P. Pileni, Langmuir, 1997, 13, 3927.

23 F. H. Jones, R. Dixon, J. S. Foord, R. G. Egdell and J. B. Pethica, Surf. Sci., 1997, 376, 367.

24 T. S. Wu, K. X. Wang, L. Y. Zou, X. H. Li, P. Wang, D. J. Wang and J. S. Chen, J. Phys. Chem. C, 2009, 113, 9114.

25 T. Otsukaab and Y. Chujo, J. Mater. Chem., 2010, 20, 10688.

26 T. S. Wu, K. X. Wang, L. Y. Zou, X. H. Li, P. Wang, D. J. Wang and J. S. Chen, J. Phys. Chem. C, 2009, 113, 9114.

27 K. Luo, S. Zhou and L. Wu, Thin Solid Films, 2009, 517, 5974.

28 T. Otsukaab and Y. Chujo, J. Mater. Chem., 2010, 20, 10688.

29 H. J. Kim, Y. G. Kang, H. G. Park, K. M. Lee, S. Yang, H. Y. Jung and D. S. Seo, Liq. Cryst., 2011, 38, 871.

30 H. G. Park, H. J. Kim, H. Y. Jeong, S. Yang, Y. G. Kang, H. J. Lee, B. Y. Oh, B. Y. Kim, Y. H. Kim, Y. P. Park, J. M. Han and D. S. Seo, Mol. Cryst. Liq. Cryst., 2012, 553, 90.

31 F. Haraguchi, K. Inoue, N. Toshima, S. Kobayashi and K. Takatoh, Jpn. J. Appl. Phys., 2007, 34, L796.

32 S. Sano, T. Miyama, K. Takatoh and S. Kobayashi, Proc. SPIE 6135, Liquid Crystal Materials, Devices, and Applications XI, February 23 2006, 613501.
33 T. Joshi, J. Prakash, A. Kumar, J. Gangwar, A. K. Srivastava, S. Singh and A. M. Biradar, J. Phys. D: Appl. Phys., 2011, 44, 315404.

34 Y. Reznikov, O. Buchnev, O. Tereshchenko, V. Reshetnyak, A. Glushchenko and J. West, Appl. Phys. Lett., 2003, 82, 1917.

35 E. Ouskova, O. Buchnev, V. Reshetnyak, Y. Reznikov and H. Kresse, Liq. Cryst., 2003, 30, 1.

36 S. K. Prasad, K. L. Sandhya, G. G. Nair, U. S. Hiremath, C. V. Yelamaggad and S. Sampath, Liq. Cryst., 2006, 33, 1121.

37 S. Hiller, A. M. Biradar and W. Haase, Phys. Rev. E: Stat. Phys., Plasmas, Fluids, Relat. Interdiscip. Top., 1996, 53, 641.

38 S. Kaur, A. K. Thakur, R. Chauhan, S. S. Bawa and A. M. Biradar, J. Appl. Phys., 2004, 96, 2547.

39 S. S. Bawa, A. M. Biradar and S. Chandra, Phys. Status Solidi A, 1987, 102, 829.

40 K. H. Yang, T. C. Chiew and S. Osofsky, Appl. Phys. Lett., 1989, 55, 125.

41 H. Mada, Jpn. J. Appl. Phys., 1990, 29, L123.

42 K. H. Yang, T. C. Chieu and S. Osofsky, Appl. Phys. Lett., 1989, 55, 125.

43 Z. Zou, N. A. Clark and M. A. Handschy, Ferroelectrics, 1991, 121, 147.

44 G. Barbero and G. Durand, J. Appl. Phys., 1990, 67, 2678.

45 S. H. Perlmutter, D. Doroski and G. Moddel, Appl. Phys. Lett., 1996, 69, 1182.

46 V. A. Tsvetkov and O. V. Tsvetkov, Mol. Cryst. Liq. Cryst. Sci. Technol., Sect. A, 2001, 368, 625.

47 P. S. Chen, C. C. Huang, Y. W. Liu and C. Y. Chao, Appl. Phys. Lett., 2007, 90, 211111.

48 P. S. Chen, C. C. Huang, Y. W. Liu and C. Y. Chao, Mol. Cryst. Liq. Cryst., 2009, 507, 202.

49 W. T. Chen, P. S. Chen and C. Y. Chao, Jpn. J. Appl. Phys., 2009, 48, 015006.

50 H. H. Liu and W. Lee, Appl. Phys. Lett., 2010, 97, 023510.

51 P. Arora, A. Mikulko, F. Podgornov and W. Haase, Mol. Cryst. Liq. Cryst., 2009, 502, 1.

52 A. Malik, J. Prakash, A. Kumar, A. Dhar and A. M. Biradar, J. Appl. Phys., 2012, 112, 054309.

53 T. Joshi, A. Kumar, J. Prakash and A. M. Biradar, Liq. Cryst., 2010, 37, 1433. 